\title{
Topical Tranexamic Acid Versus Topical Ascorbic Acid in the Treatment of Melasma: Randomized Clinical Trial
}

\author{
Amer $\mathbf{M}^{1}$, Ibrahim $\mathrm{S}^{1}$, Amer $\mathrm{A}^{1 *}$ and Eid $\mathrm{D}^{2}$ \\ ${ }^{1}$ Dermatology, Venereology and Andrology, Faculty of Medicine, Zagazig University, \\ Egypt \\ ${ }^{2}$ Faculty of Medicine, Zagazig University, Egypt
}

*Corresponding author: Amin Amer, Assistant Professor of Dermatology,

\section{Research article \\ Volume 4 Issue 4}

Received Date: September 29, 2019

Published Date: October 28, 2019

DOI: $10.23880 /$ cdoaj- 16000192

Venereology and Andrology, Faculty of Medicine, Zagazig University, Egypt, Email: aminamer74@gmail.com

\section{Abstract}

Background: Melasma is an acquired hypermelanosis characterized by symmetrical, irregular light-to-dark-brown macules \& patches on sun-exposed area, especially on the face. Tranexamic acid is a plasmin inhibitor which inhibits UV induced plasmin activity \& subsequently reduces melanogenesis in melanocyte. Ascorbic acid affects the monopherase activity of tyrosinase thus reducing melanin synthesis. In addition, ascorbic acid has a photoprotective effect, preventing the absorption of ultraviolet radiation (UVA \&UVB). The aim of this study is to evaluate \& compare the clinical efficacy plus adverse effects of topical tranexamic acid and topical Ascorbic acid in the treatment of melasma.

Materials and Methods: A total of fifty eight (58) Egyptian female patients are enrolled in this study. This is left-right randomized clinical trial. The total duration of the study was 12 weeks. At baseline, a photo will be taken and the patients will be instructed to use, at night, a wet dressing using TA solution ( 3 ampoules, total $15 \mathrm{ml}$ of Tranexamic Acid®) (500 $\mathrm{mg} / 5 \mathrm{ml}$ ), was applied on the left side of the face. and Ascorbic acid cream once daily on the right side of the face.

Results: We found no statistical significance differences between Rt side (Ascorbic acid treated side) and Lt side (Tranexamic acid treated side) in MASI score at any times of treatment also there were no statistical significance differences between them in \% of change in MASI score. Regarding change in the same side there were statistical significant reduction in MASI score in both Rt side (Ascorbic acid treated side) and Lt side (Tranexamic acid treated side). Side effects were burning sensation and erythema which subside quickly on both sides.

Keywords: Melasma; Ascorbic acid; Tranexamic acid

Abbreviations: HQ: Hydroquinone; TA: Tranexamic Acid. 


\section{Clinical Dermatology Open Access Journal}

\section{Introduction}

Melasma is an acquired pigmentary disorder characterised by more or less symmetrically distributed, medium- to dark-brown macules with well-defined geographic borders, affecting sun-exposed areas particularly forehead, cheeks, temples and upper lip [1]. It typically affects women of reproductive age with Fitzpatrick skin types IV-VI, though the condition can occur in men also [2].

Although the aetiology and pathogenesis of melasma are not completely understood, there are several factors involved. Familial occurrence in $30 \%$ of the cases suggests genetic predisposition. Ultraviolet radiation is an important factor, but other factors are also related, such as pregnancy, the use of oral contraceptives, phototoxic drugs, and thyroid dysfunction. Interactions between cutaneous vasculature and melanogenesis were established. However, most cases in men and one third of the cases of women present idiopathic feature [3].

The objectives of melasma therapy should be directed for protection from sunlight and depigmentation. Pigment reduction is achieved by using chemicals that interfere with various steps of the melanogenesis pathways via: (i) the retardation of melanocytes proliferation; (ii) the inhibition of melanosome formation and melanin synthesis; and (iii) the enhancement of melanosome degradation [4].

Hydroquinone (HQ) remain common used topical depigmenting agent. There have been concerns about the side effects and long term safety of HQ; hence the need to develop alternate treatment options [2]. In recent times, some researchers found that tranexamic acid (TA), a traditional haemostatic drug, has hypo-pigmentary effect on melasma lesions and also prevents UV-induced pigmentation [5].

Tranexamic acid (TA), that is, trans-4-amino methyl cyclohexane carboxylic acid, is a hydrophilic agent used as an antifibrolytic agent for over 30 years. Studies in human melanocyte and keratinocyte cultures have revealed that TA inhibits melanin synthesis in melanocytes by interfering with the interaction of melanocytes and keratinocytes through inhibition of plasminogen/plasmin system [2].

The intracellular release of arachidonic acid, a precursor of prostanoid, and the level of alphamelanocyte-stimulating hormone (MSH) increase as the result of plasmin activity. These two substances can activate melanin synthesis. Therefore, the anti-plasmin activity of TA is thought as the main mechanism of hypopigmentary effect of this agent [5].

Tranexamic acid was claimed to have antiinflammatory and whitening effects when administered either systemically or topically. However, systemic tranexamic acid is not completely safe with reports of serious complications such as deep venous thrombosis, pulmonary embolism, cerebral artery thrombosis and embolism, and coronary artery thrombosis and embolism. On the other hand, TA should be safer when used topically due to the absence of systemic absorption. Reported intralesional localized micro-injection of TA as a potentially new, effective and safe therapeutic modality for melasma. Despite limited controlled trials with objective measurements for testing the lightening abilities of topical TA, it is popular as a cosmetic ingredient and available commercially in combined formulas with other whitening agents [6]. Ascorbic acid affects the monopherase activity of tyrosinase via its ability to reduce the enzymatically generated $o$-quinones, thus reducing melanin synthesis.

In addition, ascorbic acid has a photo-protective effect, preventing the absorption of ultraviolet radiation (both UVA and UVB). It is retained in the epidermis, which is an advantage over sunscreens that are easily removed. It has an antioxidant effect (one of the effects first described on skin), preventing the production of free radicals that trigger melanogenesis. It also minimizes oxidized melanin formation, changing the pigmentation from black to tan. Consequently, ascorbic acid may have an important effect on hyperpigmentation, such as melasma [7].

\section{Patients and Methods}

This study was carried out at the outpatient clinics of Dermatology, Venereology and Andrology Department, Faculty of Medicine, Zagazig University Hospitals in the period from January 2016 till January 2017. Fifty eight female patients aged 26 - 52 years with melasma were enrolled in the study. The study had the approval of The Institutional Review Board (IRB) at Zagazig University. An informed consent was taken from each patient.

\section{Inclusion criteria}

- Age above 18 years.

- Mild, Moderate and severe melasma with a malar distribution.

- Patients with all type of melasma (epidermal, dermal and mixed). 


\section{Clinical Dermatology Open Access Journal}

\section{Exclusion criteria:}

1. Pregnant or nursing women.

2. Women who is taking contraceptive pills at the time of the study or during the past 12 months.

3. Any known bleeding disorders or the concomitant use of anticoagulants.

4. Women on any concurrent therapy for melasma.

5. Patients that are using any topical therapy for melasma 1 month before.

\section{Full history was taken from each case including}

1. Personal history (name, gender and age).

2. Present history which included onset, course, duration, history of drug intake, pregnancy, sun exposure, previous treatment (e.g. whitening creams, chemical peeling, mesotherapy and laser), post treatment outcome, complications (e.g. local skin irritation and $\mathrm{PIH}$ ) and recurrence after treatment.

3. Past history of systemic diseases (e.g. thyroid disease, coagulopathy.. etc)

\section{All patients were subjected to}

1. General examination.

2. Dermatological examination to assess skin type, site, type and severity of melasma assessed by a modified MASI scoring system. Wood's light was used to assess the depth of the pigment.

3. Melasma was classified into epidermal, dermal, and mixed types, based on the location of pigment determined clinically by the colour of pigmentation and by Wood's lamp examination.

4. Epidermal melasma appears dark brown in colour. Under Wood's light, a darkening of colour occurred during examination. In dermal melasma, there is greyish blue pigmentation which did not show accentuation during Wood's light examination. Mixed melasma is a combination of epidermal and dermal melasma. Colour enhancement with Wood's light is seen in some places of the skin, but not others.

A total of fifty eight (58) female patients are enrolled. This is left-right randomized clinical trial. The total duration of the study is 12 weeks. At baseline, a photo will be taken and the patients will be instructed to use, at night, a wet dressing using TA solution ( 3 ampoules, total $15 \mathrm{ml}$ of Tranexamic Acid ${ }^{\circledR}(500 \mathrm{mg} / 5 \mathrm{ml})$, was applied on the left side of the face. and a wet dressing using Ascorbic acid once daily on the right side of the face. According to Wood's light examination, the type of melasma in patients was divided into: epidermal type, dermal type and mixed type.

\section{Clinical assessment}

Digital colour facial photographs were taken using a Canon digital camera (IXUS 160). Anterior, left and right profile views were obtained at baseline, 6 weeks, 12 weeks and after 3 months. The results were assessed at the end of treatment using the modified MASI scoring system. Patient satisfaction and any adverse events were also recorded. Modified MASI scoring: Physicians assessed the results using modified MASI scoring system. The MASI score is calculated by subjective assessment of 2 factors: area (A) of involvement and darkness (D), With the forehead (f), right malar region ( $\mathrm{rm}$ ), left malar region ( $\mathrm{lm}$ ), and chin (c) corresponding to $30 \%, 30 \%, 30 \%$, and $10 \%$ of the total face, respectively. The total score range is 0 to 24, (Figure 1) [8]. Area and darkness are scored as follows:

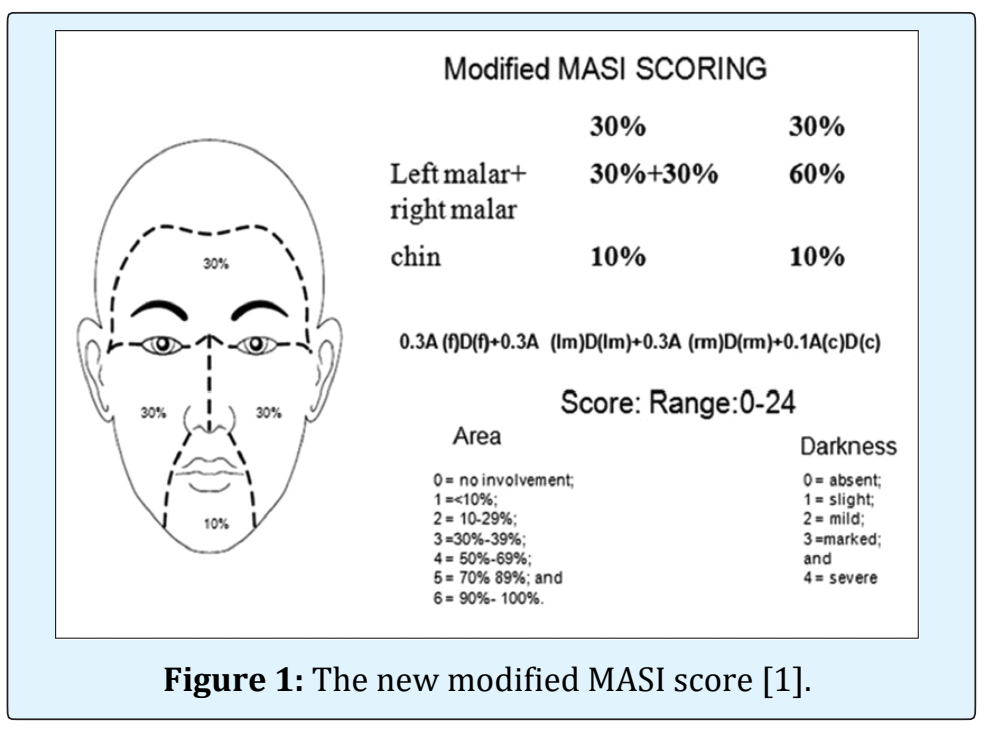




\begin{tabular}{|c|c|}
\hline Area of involvement (A) & Darkness (D) \\
\hline $0=$ absent & $0=$ absent \\
\hline $1=$ less than $10 \%$ & $1=$ slight \\
\hline $2=10 \%-29 \%$ & $2=$ mild \\
\hline $3=30 \%-49 \%$ & $3=$ marked \\
\hline $4=50 \%-69 \%$ & $4=$ severe \\
\hline $5=70 \%-89 \%$ & \\
\hline $6=90 \%-100 \%$ & \\
\hline
\end{tabular}

Modified MASI total score $=0.3 \mathrm{~A}(\mathrm{f}) \mathrm{D}+0.3 \mathrm{~A}(\mathrm{~lm}) \mathrm{D}$ $(\mathrm{lm})+0.3 \mathrm{~A}(\mathrm{rm}) \mathrm{D}(\mathrm{rm})+0.1 \mathrm{~A}(\mathrm{c}) \mathrm{D}(\mathrm{c})[8]$.

\section{Methods}

Before treatment, an informed consent was taken from all patients. Each patient was asked about his goals, concerns and expectations about the treatment to avoid unrealistic expectations. Possible side effects were explained such as pain, erythema and burning sensation after product application. Sunscreen was strictly used throughout treatment and afterwards. The patients were instructed to use, at night, a wet dressing using TA solution ( 3 ampoules, total $15 \mathrm{ml}$ of Tranexamic Acid $\AA$ (500 mg/5 ml), was applied on the left side of the face. and $10 \%$ Ascorbic acid cream (ascorbic acid powder in cream base prepared by local pharmacist) once daily on the right side of the face. The patients were advised to avoid excessive sun exposure and to apply a broad spectrum sunscreen with a sun protection factor of 15 or higher in the morning. Patients were observed monthly for 3 months during treatment and monthly for three months in the follow up period.

Therapeutic response: the degree of improvement was categorized as follows; very good response, $>75 \%$ improvement; good response, $50 \%$ to $<75 \%$ improvement; moderate response, $25 \%$ to $<50 \%$ improvement; mild response, $<25 \%$ improvement; No response, no improvement. Each case was followed up for 3 months to look for further improvement/relapse [1].

Patient satisfaction: A questionnaire was given to patients at the end of treatment to assess their degree of improvement as mild ( $<25 \%$ improvement), moderate $(25 \%$ to $<50 \%)$, good $(50 \%$ to $<75 \%)$ and very good ( $>75 \%$ improvement).

Side effects: Any possible side effects observed such as pain, erythema and burning sensation during treatment were recorded.
Statistical analysis: Data were checked, entered and analysed by using SPSS (version 19). Data were represented as mean \pm SD for quantitative variables. Number and percentage were used for categorical variables. The one way ANOVA test, Chi square test and paired $\mathrm{t}$ - test were used to assess results. $\mathrm{P}<0.001$ was considered statistically significant.

\section{Results}

This study included 58 female patients, their ages ranged from 26 to 52 years with a mean of $39.43 \pm 5.89$. Twenty one patients had skin phototype Ш (36.2\%), 35 patients with phototype IV (60.3\%) and 2 patients with phototype V (3.5\%).

The duration of melasma ranged from 5 month - 16 years with a mean of $5.54 \pm 4.58$. According to Wood's light examination, the type of melasma in patients was: 20 patients $(34.4 \%)$ having mainly epidermal type, 11 patients (19\%) having mainly dermal type and 27 patients $(46.6 \%)$ having mixed type. Family history was detected in 32 patients (55.2\%). Effect of sun exposure was found in 58 patients (100\%). Hormonal contraception was reported in 9 patients $(15.5 \%)$.

\section{Demographic and Clinical data of the studied group}

This table shows that the age of the studied group ranged from 26 - 52 years with mean 39.43 years. Regarding sex all the studied group were female (Table 1).

\begin{tabular}{|c|c|c|}
\hline Variable & $(\mathbf{n = 5 8 )}$ \\
\hline \multicolumn{3}{|c|}{ Age : (year) } \\
\hline Mean \pm SD & $39.43 \pm 5.89$ & \\
\hline Range & $26-52$ & No \\
\hline Variable & Sex & 100 \\
\hline \multicolumn{3}{|c|}{58} \\
\hline Female & 0 & 0 \\
\hline Male & No
\end{tabular}

Table 1: Demographic data of the studied group.

This table shows that the duration of melasma among the studied group ranged from 5 months to 16 years with mean 5.54 years. Regarding Fitzpatrick skin type 60.3\% was type IV, melasma type $46.6 \%$ was of mixed type and 74.1\% had previous treatment (Table 2). 


\begin{tabular}{|c|c|c|}
\hline Variable & \multicolumn{2}{|c|}{$(n=58)$} \\
\hline \multicolumn{3}{|c|}{ Duration (year) } \\
\hline Mean \pm SD & $5.54 \pm 4.58$ & \\
\hline Range & $5 m-16 y$ & \\
\hline Variable & No & $\%$ \\
\hline \multicolumn{3}{|c|}{ Skin type } \\
\hline III & 21 & 36.2 \\
\hline IV & 35 & 60.3 \\
\hline $\mathrm{V}$ & 2 & 3.5 \\
\hline \multicolumn{3}{|c|}{ Melasma type } \\
\hline Dermal & 11 & 19 \\
\hline Epidermal & 20 & 34.4 \\
\hline Mixed & 27 & 46.6 \\
\hline \multicolumn{3}{|c|}{ Previous ttt } \\
\hline No & 15 & 25.9 \\
\hline Yes & 43 & 74.1 \\
\hline
\end{tabular}

Table 2: Demographic data of the studied group.

\section{History and risk factors in the studied group}

This table shows that $55.2 \%$ of the studied group had +ve family history. Regarding causes of melasma 55.2\% related to pregnancy, $100 \%$ related to sun exposure and $15.5 \%$ were related to oral contraception (Table 3).

\begin{tabular}{|c|c|c|}
\hline \multirow{2}{*}{ Variable } & \multicolumn{2}{|c|}{ (n=58) } \\
\cline { 2 - 3 } & & $\mathbf{0}$ \\
\hline Family history: & 26 & 44.8 \\
\hline No & 32 & 55.2 \\
\hline Yes & & \\
\hline Ro & 26 & 44.8 \\
\hline Nes & 32 & 55.2 \\
\hline No & & 0 \\
\hline$Y e s$ & 0 & 100 \\
\hline Relation with sun exposure: & 58 & \\
\hline Relation with Oral contraception: & & 84.5 \\
\hline No & 49 & 15.5 \\
\hline
\end{tabular}

Table 3: History and risk factors of the cases group.

\section{Therapeutic response}

Fifty eight female patients were enrolled in the study. Thirty subjects dropped out due to lack of compliance during treatment course and follow up.

The response to treatment was assessed using modified MASI scoring system at baseline, 6 weeks, 12 weeks and after 3 months. Degree of improvement was assessed by physician assessment and patient satisfaction.
This table shows that there were no statistical significance differences between Rt side (Ascorbic acid treated side) and Lt side (Tranexamic acid treated side) in MASI score at any times of treatment also there were no statistical significance differences between them in \% of change in MASI score. Regarding change in the same group there were statistical significant reduction in MASI score in both Rt side (Ascorbic acid treated side) and Lt side (Tranexamic acid treated side) (Table 4). 


\begin{tabular}{|c|c|c|c|c|c|}
\hline Time & Variable & $\begin{array}{c}\text { Rt side (Ascorbic acid treated } \\
\text { side) }(n=58)\end{array}$ & $\begin{array}{c}\text { Lt side ( Tranexamic acid } \\
\text { treated side) }(n=58)\end{array}$ & MW & $\mathbf{p}$ \\
\hline \multirow{4}{*}{ Base line: } & MASI: & & & & \\
\hline & Mean \pm SD & $2.73 \pm 1.32$ & $2.62 \pm 1.27$ & \multirow{3}{*}{0.32} & \\
\hline & median & 2.7 & 2.85 & & 0.75 \\
\hline & Range & $0.6-5.4$ & $0.6-4.5$ & & NS \\
\hline \multirow{4}{*}{6 weeks: } & MASI: & $(n=45)$ & $(n=45)$ & \multirow{4}{*}{0.5} & \\
\hline & Mean \pm SD & $1.68 \pm 0.87$ & $1.65 \pm 0.91$ & & \\
\hline & Median & 1.8 & 1.5 & & 0.62 \\
\hline & Range & $0.3-3.6$ & $0.3-3.6$ & & NS \\
\hline \multirow{4}{*}{12 weeks: } & MASI: & $(n=45)$ & $(n=45)$ & \multirow{4}{*}{1.31} & \\
\hline & Mean \pm SD & $0.89 \pm 0.48$ & $0.87 \pm 0.60$ & & \\
\hline & Median & 0.9 & 0.6 & & 0.19 \\
\hline & Range & $0.3-3$ & $0.3-2.7$ & & NS \\
\hline \multirow{4}{*}{3 months } & MASI: & $(n=45)$ & $(\mathrm{n}=45)$ & \multirow{4}{*}{0.1} & \\
\hline & Mean \pm SD & $1.14 \pm 0.64$ & $1.24 \pm 0.80$ & & \\
\hline & Median & 0.9 & 0.9 & & 0.92 \\
\hline & Range & $0.3-3$ & $0.3-3.6$ & & NS \\
\hline \multicolumn{2}{|c|}{ Friedman } & 94.13 & 108.36 & & \\
\hline \multicolumn{2}{|c|}{$\mathbf{P}$} & $<0.001^{* *}$ & $<0.001^{* *}$ & & \\
\hline \multicolumn{2}{|c|}{$\%$ of change: } & $(n=45)$ & $(n=45)$ & \multirow{4}{*}{0.61} & \\
\hline \multicolumn{2}{|c|}{ Mean \pm SD } & $-43.11 \pm 54.54$ & $-49.02 \pm 30.12$ & & \\
\hline \multicolumn{2}{|c|}{ Median } & -60 & -50 & & 0.54 \\
\hline \multicolumn{2}{|c|}{ Range } & $-093.33-200$ & -136.67 & & NS \\
\hline
\end{tabular}

Table 4: MASI score at different sessions in both sides among the studied group.

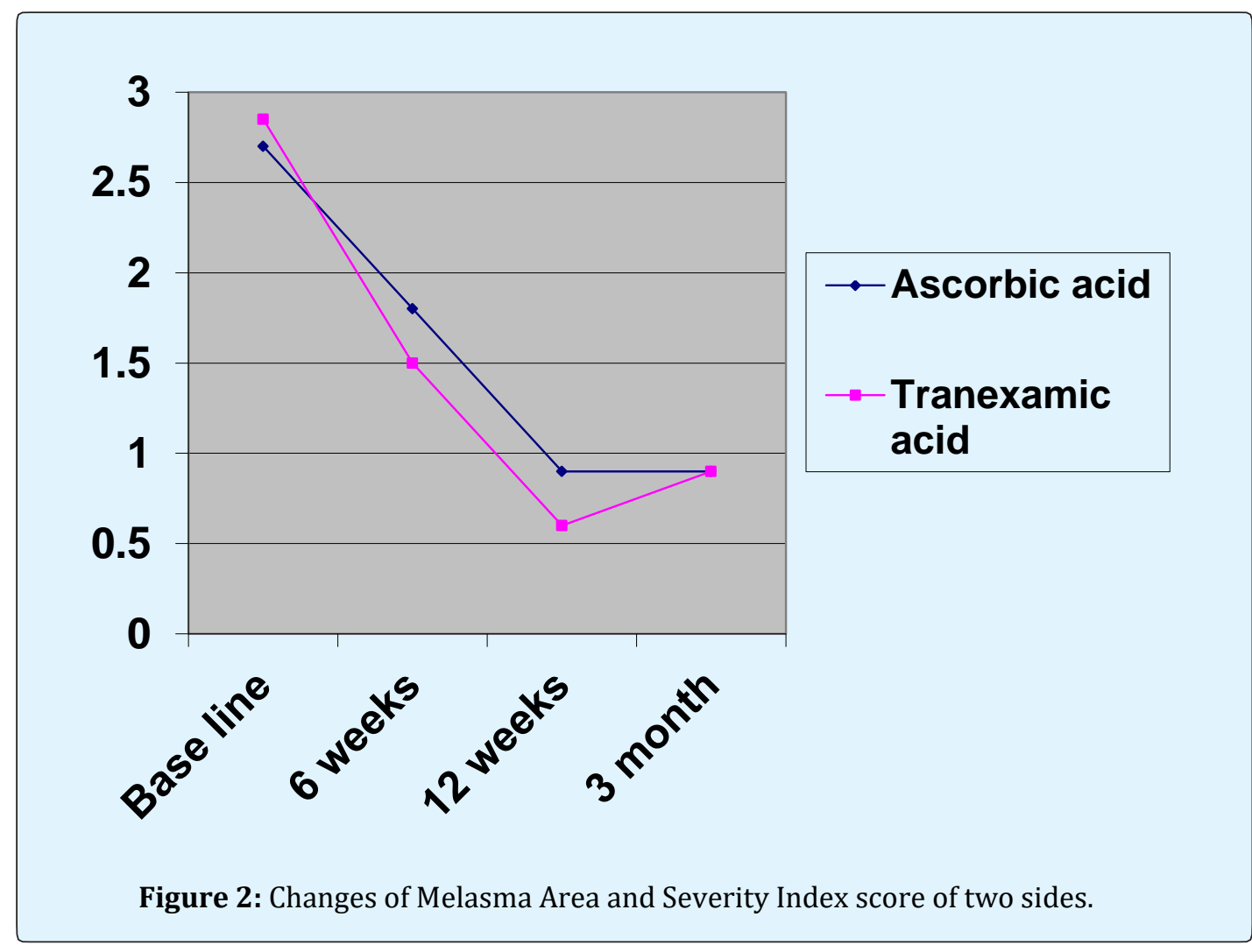




\section{Clinical Dermatology Open Access Journal}

Degree of improvement by physician assessment and patient assessment significance differences between Rt side and Lt side in patient satisfaction or physician assessment (Table 5).

This table shows that there were no statistical

\begin{tabular}{|c|c|c|c|c|c|c|}
\hline \multirow[t]{2}{*}{ Variable } & \multicolumn{2}{|c|}{$\begin{array}{c}\text { Rt side } \\
\text { (Ascorbic acid) } \\
(n=45)\end{array}$} & \multicolumn{2}{|c|}{$\begin{array}{c}\text { Lt side } \\
\text { Tranexamic acid) } \\
(\mathrm{n}=45)\end{array}$} & \multirow[t]{2}{*}{$\chi^{2}$} & \multirow[t]{2}{*}{$\mathbf{P}$} \\
\hline & No & $\%$ & No & $\%$ & & \\
\hline \multicolumn{7}{|c|}{ Patient satisfaction: } \\
\hline$(75-100 \%)$ Very good & 6 & 13.3 & 2 & 4.4 & \multirow{4}{*}{6.77} & 0.08 \\
\hline$(50-<75 \%)$ Good & 11 & 24.4 & 18 & 40 & & NS \\
\hline$(25-<50 \%)$ Moderate & 26 & 57.8 & 19 & 42.2 & & \\
\hline Mild $(<25 \%)$ & 2 & 4.4 & 6 & 13.3 & & \\
\hline \multicolumn{7}{|c|}{ Physician assessment: } \\
\hline Very good (75-100\%) & 10 & 22.2 & 6 & 13.3 & \multirow{4}{*}{4.04} & 0.26 \\
\hline Good (50 - <75\%) & 24 & 53.3 & 24 & 53.3 & & NS \\
\hline Moderate $(25-<50 \%)$ & 11 & 24.4 & 12 & 26.7 & & \\
\hline Mild $(<25 \%)$ & 0 & 0 & 3 & 6.7 & & \\
\hline
\end{tabular}

Table 5: Degree of improvement by patient satisfaction and physician assessment of the studied group.

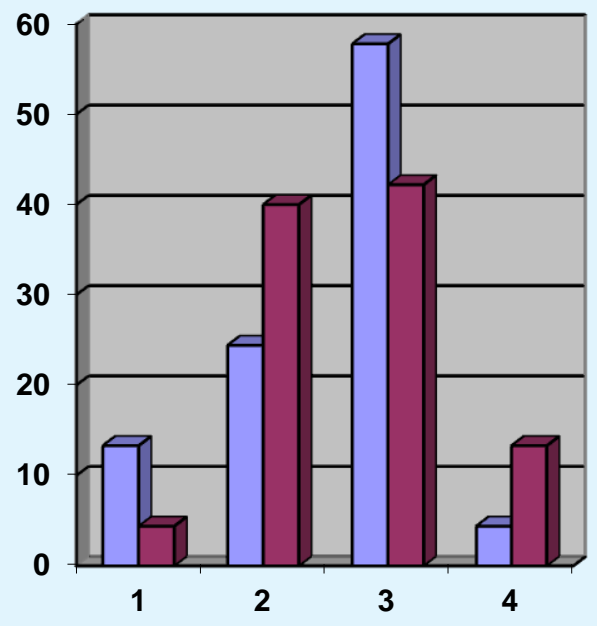

$\square$ Ascorbic acid

$\square$ Tranexamic acid

Figure 3: Patient self-assessment of improvement at week 12. Patients were asked to grade their overall improvement as $1=>75 \%$ lightening (Very good), $2=50-75 \%$ (good), $3=25-50 \%$ (Moderate), and $4=0-25 \%$ lightening (Mild). 


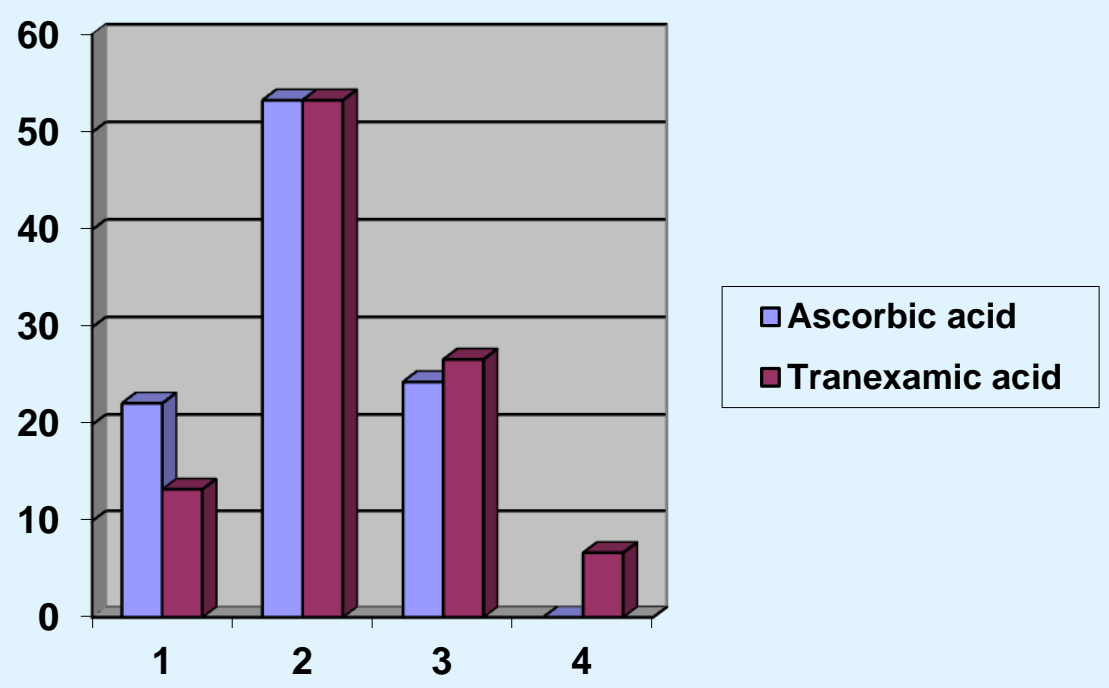

Figure 4: Physician assessment of improvement at week 12 based on the patients photos. Physician were asked to grade their overall improvement as $1=>75 \%$ lightening (Very good), $2=50-75 \%$ (good), $3=25-50 \%$ (Moderate), and $4=0-25 \%$ lightening (Mild).

\section{Discussion}

Melasma affects millions of people worldwide and is found most commonly in women with Fitzpatrick skin photo-types III-V. The common contributing factors include genetic predisposition, pregnancy, oral contraceptives, endocrine dysfunction, hormonal treatments, drugs containing phototoxic agents, and stress. Exposure to ultraviolet light is a major triggering or aggravating factor for melasma [9]. Presently, there is no universally effective procedure or agent for melasma treatment despite various therapeutic modalities already available such as laser ablation, chemical peeling or depigmenting agents that are used to lighten melasma to some degree. Other than conservative measures such as prevention of eliciting factors, hydroquinone, the most commonly used topical depigmenting agent, is effective at high concentration (4-5\%). However, cosmetically unacceptable side effects such as leukoderma, erythema and ochronosis can occur [6].

Tranexamic acid (TA) is a hemostatic drug. This agent seems to be effective in treating melasma through its antiplasmin activity and subsequent decreased levels of arachidonic acid and alpha-MSH hormone. The potential adverse effects make clinicians hesitant to prescribe oral TA to patients, although the dose of TA for dermatologic conditions is much lower than the conventional one of oral TA used in other clinical fields. Moreover, the longterm safety of oral TA has not yet been established. Topical application of TA has its strong point from this point of view. It is essentially devoid of significant adverse effects, except for possible local complications, such as irritation or an allergic reaction $[10,11]$.

Clinical trials using localized intradermal microinjections of TA or trans -epidermal delivery of TA with microneedling techniques have shown favourable results in the treatment of melasma. However, microinjection or microneedling is inevitably accompanied by pain. Needling can also irritate melasma itself. In contrast, topical agents containing TA are easy to use, require no anaesthesia, and can be used for a prolonged period of time. Therefore, an easy method of topical application, such as a cosmeceutical form, may be favoured for long-term and maintenance use of TA for skin conditions [10].

Ascorbic acid has antioxidant properties and affects melanogenesis by reducing dopaquinone to DOPA and preventing free-radical production and absorption of UVR. Mostly used topical preparations have ascorbic acid in $0.3-10 \%$ concentrations but $15 \%$ and $20 \%$ concentrations can also be used. Topical ascorbic acid cream is a safe and effective alternative to conventional treatments for melasma. In a study comparing efficacy of 


\section{Clinical Dermatology Open Access Journal}

$4 \%$ hydroquinone vs. $5 \%$ ascorbic acid in melasma it was concluded that $68.7 \%$ patients using $4 \%$ hydroquinone developed side effects as compared to only $6.2 \%$ patients using $5 \%$ ascorbic acid. So $5 \%$ ascorbic acid is better tolerated and may therefore be considered as first line therapy for patients wishing to try the safest treatment first [12].

This study was conducted to evaluate and compare the efficacy of two different topical agents in the treatment of melasma. It included topical TA and topical ascorbic acid. To our knowledge, this is the first study comparing these two different agents in the management of melasma.

A total of fifty eight (58) female patients are enrolled in this study. This is left-right randomized clinical trial. The total duration of the study is 12 weeks. At baseline, a photo will be taken and the patients will be instructed to use, at night, a wet dressing using TA solution (3 ampoules, total $15 \mathrm{ml}$ of Tranexamic Acid $\AA(500 \mathrm{mg} / 5$ $\mathrm{ml}$ ), was applied on the left side of the face. and Ascorbic acid cream once daily on the right side of the face.

The present study revealed promising results about using topical TA. The severity of melasma was reduced after treatment with topical TA in many patients. The difference in the modified MASI score in this study, at base line, after 6 weeks, after 12 weeks and 3 month with topical TA was statistically significant $(\mathrm{p}<0.001)$. By the modified MASI score, three patients $(6.7 \%)$ had mild response, twelve patients $(26.7 \%)$ had moderate response, twenty four patients (53.3\%) had good response and six patients (13.3\%) had very good response. According to patient satisfaction; six patients (13.3\%) reported their improvement as mild, nineteen patients $(42.2 \%)$ reported their improvement as moderate, eighteen patients $(40 \%)$ as good and two patients $(4.4 \%)$ as very good.

The results of this study were close to a split-face trial of Ebrahimi and Naeini [5] who compare the efficacy of topical 3\% TA with topical 3\% hydroquinone $0.01 \%$ dexamethasone. They concluded that the topical TA was effective and safe therapeutic option. The patients'selfassessment of melasma improvement was evaluated at week $12 ; 3 \%, 27.3 \%, 30.3 \%$, and $39.4 \%$ of patients graded melasma improvement of the side which was treated with TA as excellent good, fair, and poor, respectively. The study of Ebrahimi and Naeini [5]. Showed less good results compared to the present study $(4.4 \%$ rated very good improvement, $40 \%$ rated good improvement, $42.2 \%$ moderate, $13.3 \%$ rated mild improvement).This may be explained by the use of higher concentration of TA (10\%) compared with the study of Ebrahimi and Naeini [5]. Side effects were transient and well tolerated in both studies.

In a split-face trial, Na Ayuthaya, et al. [6] evaluated the efficacy of topical 5\% TA in comparison with its vehicle. This study revealed that physician global evaluation results demonstrated no significant pigmentary alteration including the erythema between the TA-treated and control sides of the face by the end of the study. For patients' global evaluation of lightening of pigment. 1 out of $21(4.7 \%)$ found excellent results for both sides of the face, 8 out of $21(38.9 \%)$ felt moderate lightening on both sides, 5 out of 21(23.8\%) had marginal results, while $2(9.5 \%)$ achieved no improvement at all. And in this study 2 patients (4.4\%) reported their improvement as very good, 18 patients $(40 \%)$ reported their improvement as good, 19 patients $(42.2 \%)$ as moderate and 6 patients (13.3\%) as mild which showed good results compared to Kanechorn Na Ayuthaya study. Side effects in both study were burning sensation and erythema which subside quickly.

This study also revealed promising results about using topical ascorbic acid. The severity of melasma was reduced after treatment with topical ascorbic acid in many patients. The difference in the modified MASI score in this study, at base line, after 6 weeks, after 12 weeks and 3 month with topical ascorbic acid was statistically significant $(\mathrm{p}<0.001)$. By the modified MASI score, eleven patients $(24.4 \%)$ had moderate response, twenty four patients $(53.3 \%)$ had good response and ten patients (22.2\%) had very good response. According to patient satisfaction; two patients (4.4\%) reported their improvement as mild, twenty six patients (57.8\%) reported their improvement as moderate, eleven patients $(24.4 \%)$ as good and six patients (13.3\%) as very good.

A double-blind randomized trial of 5\% ascorbic acid vs. $4 \%$ hydroquinone in melasma was made by EspinalPerez, et al. [13]. It showed the subjective assessment by patients to L-ascorbic acid was excellent in two patients (12.5\%), good in eight (50\%), moderate in four $(25 \%)$, and mild in two (12.5\%). The study of Espinal-Perez [13]. showed less good results compared to the present study (13.3\% rated very good improvement, $24.4 \%$ rated good improvement, $57.8 \%$ moderate, $4.4 \%$ rated mild improvement). In both study, Side effects were transient irritation which well tolerated and subside quickly.

Yenny SW [7] performed a study comparing the use of $10 \%$ L-ascorbic acid and 10\% zinc sulphate solution in the treatment of melasma. No improvement of melasma with $10 \% \mathrm{~L}$-Ascorbic acid were noted at 2 weeks therapy. 
After 4 weeks there was mild to moderate improvement. However, after 6 weeks treatment, there was moderate improvement in both treatment sites. After 2 months of treatment there was significantly more improvement with $10 \%$ L- Ascorbic acid. On day 56 of therapy, there were significant differences: $10 \%$ L-Ascorbic acid was $4.34 \pm 1.23$. In the present study after 6 weeks treatment, there was moderate improvement (1.68 \pm 0.87$)$. After 12 weeks was good improvement $(0.89 \pm 0.48)$. Side effects in patients treated with Ascorbic acid in both study included redness and pain, which resolved quickly.

There were statistical significant reduction in MASI score in both Rt side (Ascorbic acid treated side) and Lt side (Tranexamic acid treated side) but we found no statistical significance differences between Rt side (Ascorbic acid treated side) and Lt side (Tranexamic acid treated side) in MASI score at any times of treatment also there were no statistical significance differences between them in percentage of change in MASI score.

Side effects were burning sensation and erythema which subside quickly in Rt side of the face (Ascorbic acid treated side) and Lt side of the face (Tranexamic acid treated side).

As it has been demonstrated that TA may cause skin irritation as well as allergic reaction, a novel topical TA liposome formulation was developed in order to reduce irritation and improve the moisturizing effect, although it is not yet commercially available. We used easy, non-cost method of soaking using tranexamic acid solution.

Ascorbic acid is better tolerated and is almost devoid of side effects and may therefore be considered as first line therapy for patients wishing to try the safest treatment first. Vitamin C can be combined with other melasma treatments for enhanced results. It can fade melasma from a dark black to light tan while also providing additional protection from the sun.

It could be concluded that the two agents represent safe and effective treatment for melasma. The clinical response was evident after only three months and continued in the follow up period; however more use with longer follow up periods are recommended as the final response may take several months to occur.

Longer duration of therapy is recommended for better results. Further studies on a large scale of patients are recommended to determine the efficacy of TA and ascorbic acid combination with other whitening agents. This may be associated with better or faster results [14].

\section{References}

1. Budamakuntla L, Loganathan E, Suresh DH, Shanmugam S, Suryanarayan S, et al. (2013) A Randomised, Open-label, Comparative Study of Tranexamic Acid Microinjections and Tranexamic Acid with Microneedling in Patients with Melasma. J Cutan Aesthet Surg 6(3): 139-143.

2. Steiner D, Feola C, Bialeski N (2009) Study evaluating the efficacy of topical and injected tranexamic acid in treatment of melasma. Surg \& Cosm Dermatol 1(4): 174-177.

3. Shanker K, Godse K, Aurangabadker S (2014) Evidence-Based Treatment for Melasma: Expert Opinion and a Review. J Dermatol Ther 4(2): 165-186.

4. Shaikh ZI, Mashood AA (2014) Treatment of refractory melasma with combination of topical $5 \%$ magnesium ascorbyl phosphate and fluorescent pulsed light in Asian patients. Int J Dermatol 53(1): 93-99.

5. Ebrahimi B, Naeini F (2014) Topical tranexamic acid as a promising treatment for melasma. J Res Med Sci 19(8): 753-757.

6. Ayuthaya P, Niumphradit N, Manosroi A, Nakakes A (2012) Topical 5\% tranexamic acid for the treatment of melasma in Asians:A double-blind randomized controlled clinical trial. J Cosmet Laser Ther 14(3): 150-154.

7. Yenny SW, Lestari W (2012) A Study Comparing the Use of 10\% L-Ascorbic Acid and 10\% Zinc Sulfate Solution in the Treatment of Melasma. MJD 29: 38-54.

8. Sarkar R, Arora P, Kumar Garg V, Sonthalia S (2014) Melasma update. Indian Dermatol Online J 5(4): 426435.

9. Soliman M, Ramadan SH, Bassiouny D (2007) Combined trichloroacetic acid peel and topical ascorbic acid versus trichloroacetic acid peel alone in the treatment of melasma: a comparative study. J Cosmet Dermatol 6(2): 89-94.

10. Chung JY, Lee JH, Lee JH (2015) Topical tranexamic acid as an adjuvant treatment in melasma: Side-byside comparison clinical study. J Dermatolog Treat 27(4): 373-377. 
11. Bagherani N, Smoller BR (2016) Efficacy of topical tranexamic acid in the treatment of melasma. Dermatol Ther 29(6): 389-390.

12. Akram SH, Sattar F, Tahir R, Mujtaba G (2013) Efficacy of topical 4\% liquiritin compared with topical $4 \%$ liquiritin mixed in $5 \%$ ascorbic acid in the treatment of melasma. J Pakistan Associt Dermatol 23(2): 149-152.

13. Espinal-Perez LE, Moncada B, Castanedo-Cazares JP (2004) A double-blind randomized trial of 5\% ascorbic acid vs. $4 \%$ hydroquinone in melasma. Int J Dermatol 43(8): 604-607.

14. Pandya AG, Hynan LS, Bhore R, Riley FC, Guevara IL, et al. (2011) Reliability assessment and validation of the Melasma Area and Severity Index (MASI) and a new modified MASI scoring method. J Am Acad Dermatol 64(1): 78-83. 